

Revista Cientifica do Instituto Agronômico do Estado de São Paulo

Vol. 33

Campinas, setembro de 1974

N. 9

\title{
EFEITOS DA GRANULOMETRIA, FORMAS E QUAN- TIDADES DE MATERIAIS CORRETIVOS NA ACIDEZ DO SOLO $\left(^{1}\right)$
} Hermano Gargantini $\left({ }^{2}\right)$, Seção de Fertilidade do Solo, Instituto

\section{SINOP SE}

Este trabalho foi realizado com o objetivo de estudar o efeito da granulometria e da quantidade de dois materiais corretivos da acidez do solo na produçăo de milho e trigo, bem como em propriedades químicas do solo.

A parte experimental foi conduzida em casa de vegetaçăo, em vasos de Mitscherlich, com amostra de Latossolo Vermelho-Escuro orto, coletada no municipio de Itapetininga. As culturas utilizadas para medir os efeitos dos calcários foram milho e, a seguir, trigo.

Os resultados mostraram efeitos iđênticos dos đois calcários na produçăo de massa seca, para as duas culturas. Os aumentos verificados foram grandes, e năo foi observada diferença entre os dois materiais corretivos estudados, como também não foram obtidas diferenças de produções com as diversas granuiometrias empregadas, para os dois calcários.

\section{1 - INTRODUÇÃO}

$O$ estudo do problema da acidez do solo assume cada vez mais interesse face ao aumento da importância da necessidade de sua correção, para obtenção de grandes colheitas. Esse aspecto é ressaltado pélạs dúvidas existentes sobre qual material deve ser utilizado; se é mais eficiente o que contém maior ou menor porcentagem de magnésio e, também, qual a granulometria que deve apresentar o calcário.

Vários trabalhos têm procurado dar respostas a essas dúvidas. Gallo e outros (3), trabalhando com cultura de soja, mostraram que os efeitos são bastante semelhantes, não ocorrendo diferenças de prodưções quando se utilizam materiais corretivos portadores somente de cálcio ou mesmo para os de cálcio e magnésio. Mesmo para a elevação

(1) Recebido para publicaçáo em 17 de malo de $\mathbf{1 9 7 4 .}$

(2) Com bolsa de suplementaçāo do CNPq. 
dos valores de $\mathrm{pH}$, os efeitos dos dois materiais foram iguais. Shaw e Robinson (7), em trabalhos conduzidos em lisímetros, mostraram a influência do grau de finura dos calcários, concluindo que material mais grosso que 8-mesh leva de três a quatro anos para dissolver. Já o passado em peneira de 30-mesh leva dois anos e o que atravessa a malha 60-mesh dissolve-se em um ano. Nesse mesmo trabalho, os autores mostram que o calcário dolomítico se torna tão eficiente quanto o calcário calcítico quando a sua granulometria se apresenta mais fina do que a deste último. Meyer e Volk (6) afirmam que é mais importante o tamanho das partículas do corretivo do que a própria natureza do material.

Com a finalidade de estudar o efeito competitivo de dois materiais corretivos da acidez do solo, em função de diversas granulometrias e quantidades, foi conduzido o experimento aqui relatado.

\section{2 - MATERIAIS E METODOS}

O ensaio foi conduzido em casa de vegetação e em vasos de Mitscherlich. O solo utilizado proveio dos $20 \mathrm{~cm}$ superficiais de um Latossolo Vermelho-Escuro, orto, do municipio de Itapetininga. A análise química e granulométrica apresentaram os seguintes resultados:

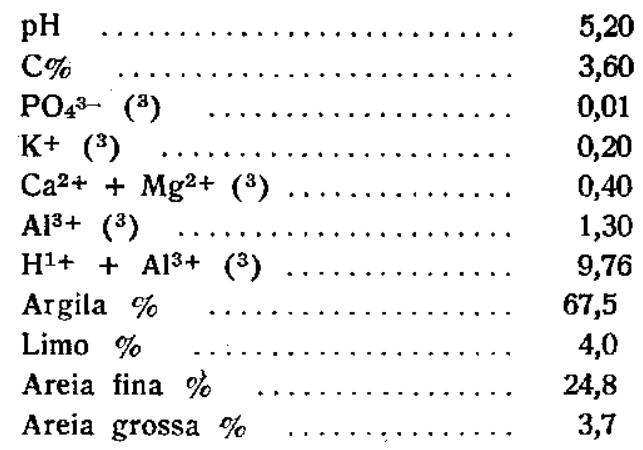

Todos os vasos receberam adubação uniforme, nos níveis $50-120$ $140 \mathrm{~kg} / \mathrm{ha}$ de $\mathrm{N}, \mathrm{P}_{2} \mathrm{O}_{5}$ e $\mathrm{K}_{2} \mathrm{O}$, nas formas de sulfato de amônio, superfosfato simples e cloreto de potássio, respectivamente. Essa adubação aplicada aos vasos corresponde às quantidades de 1,0, 2,4 e 1,6 $\mathrm{g}$ de $\mathrm{NP}_{2} \mathrm{O}_{5}$ e $\mathrm{K}_{2} \mathrm{O}$. 
Neste trabalho utilizou-se o delineamento experimental de blocos inteiramente casualizados, com três repetições e os tratamentos constantes do quadro 1.

Os materiais corretivos utilizados foram um calcário calcítico e um dolomítico, cuja análise química apresentou os seguintes resultados:

$\begin{array}{llcr} & & \mathrm{C} a \mathrm{O} & \mathrm{MgO} \\ \text { Calcário dolomítico } & \ldots \ldots \ldots & 26,8 \% & 19,3 \% \\ \text { Calcário calcítico } & \ldots \ldots \ldots \ldots & 43,2 \% & 3,8 \%\end{array}$

Os materiais, de acordo com os tratamentos, foram passados totalmente através de peneiras de malhas $10,18,35,40$ e 50-mesh, partindo de material que passou $100 \%$ na peneira 10 e $50 \%$ na malha de 50-mesh, conforme exigência contida no Dacreto-Lei n. ${ }^{\circ} 50.146$, de 28 de janeiro de 1961 .

Os dois materiais corretivos, em cada granulometria, foram aplicados em duas quantidades, uma baseada no teor de alumínio trocável contido no solo e outra tomando em conta o $\mathrm{pH}$ e necessidade de sua clevação ao redor de 6,50. Essas quantidades calculadas foram de 1,9 e $5,7 \mathrm{ton} / \mathrm{ha}$, correspondendo a 8,0 e $23,0 \mathrm{~g} / \mathrm{vaso}$ de $6 \mathrm{~kg}$ de terra.

Os calcários, nas quantidades previstas, foram intimamente misturados com o solo dos vasos, o qual após foi umedecido e deixado em descanso por um espaço de 15 dias. Como planta-teste utilizou-se o milho, variedade Maya 3, tendo sido colocadas seis sementes por vaso, cm 15 de dezembro de 1971. A emergência deu-se em 19 do mesmo mês, sendo que em 3 de janeiro de 1972 procedeu-se ao desbaste para três plantas por vaso. $\mathrm{O}$ desenvolvimento das plantas foi normal, não tendo sido constatados ataques de pragas e moléstias.

Quando as plantas atingiram 60 dias, procedeu-se à colheita da parte aérea cortando-as bem rente ao solo. O material foi colocado em estufa a $60^{\circ} \mathrm{C}$ para secar, e depois pesado.

Após a colheita, para ser amostrado, o solo foi retirado dos vasos e passado para uma bacia plástica. Separadas as raizes, foi ele muito bem misturądo, e retirada amostra de cada um deles. Essas amostras foram submetidas a análises, de acordo com os métodos da Seção de Fertilidade do Solo (4). O solo foi retornado aos vasos. 
Tendo sido constatado pelos resultados analiticos que o solo dos tratamentos 3 a 8 ainda apresentavam aluminio trocável, mostrando que as quantidades de calcário aplicadas anteriormente não foram suficientes, novas quantidades foram aplicadas. Todos os vasos receberam nova adubação, na base de $5 \mathrm{~g}$ de sulfato de amônio, $10 \mathrm{~g}$ de superfosfato simples e $3 \mathrm{~g}$ de cloreto de potássio, e neles foram plantadas 20 sementes de trigo, variedade IAC-5, no dia 17 de abril de 1972, dando-se a emergência em 22 desse mês. Em 10 de maio procedeu-se ao desbaste, deixando-se 10 plantinhas por vaso.

A cultura desenvolveu-se bem, mantendo-se a umidade conforme descrita por Gargantini e outros (3), e sempre que havia percolado era ele retornado ao vaso. A colheita deu-se em 8 de agosto, cortando-se a parte aérea bem rente ao solo. Esse material foi seco a $60^{\circ} \mathrm{C}$ e pesado. $\mathrm{O}$ solo dos vasos foi novamente amostrado e submetido a análise para verificação de suas características quimicas.

\section{3 - RESULTADOS E DISCUSSÃO}

Os dados de produção de material seco obtidos nas culturas de milho e trigo estão arrolados no quadro 1. Os dados analíticos obtidos nas amostras de terra retiradas após a condução das culturas de milho e trigo acham-se no quadro 2.

\section{1 - ENSAIO COM MILHO}

Pelos resultados em peso de material seco obtido no ensaio com milho, verificou-se facilmente que os materiais corretivos acarretaram grandes aumentos de produção. Assim, enquanto a testemunha, sem calcário, apresentou produção média de $57,7 \mathrm{~g}$, os tratamentos com calcário produziram sempre acima de $85,0 \mathrm{~g}$. A comparação dos tratamentos 1 e 2 mostra o efeito da adubação NPK que, embora grande, não chegou a ser significativa.

Os tratamentos que receberam aplicação de corretivo, seja calcítico ou dolomítico, apresentaram produções elevadas, bem maiores que as das testemunhas, sendo diferentes estatisticamente daqueles tratamentos, porém entre si não mostraram diferenças, indicando que não houve diferença de produção para a cultura de milho entre os calcários que continham maior ou menor porcentagem de magnésio.

Não se verificaram diferenças de produção quando foram usados materiais que estavam dentro das esnecificacões one a l.ei exige ot 
Quadro 1. - Produções médias, de três repetiçōes, de massa seca de plantas de milho e trigo, obtidas no ensaio de competição entre dois calcários, em diversas granulometrias e quantidades, conduzidos em vasos que continham Latossolo Vermelho-Escuro orto

1. Testemunha geral

2. NPK, sem corretivo

3. NPK + Calc. dol. legal ( $100 \%$ pen. 10 e $50 \%$ pen. 50 para Al

4. NPK + Calc. cal. legal ( $100 \%$ pen. 10 e $50 \%$ pen. 50 para Al

5. NPK + " dolomitico pas. $100 \%$ peneira 10, para Al

6. $\mathrm{NPK}+"$ calcitico pas. $100 \%$ peneira 10 , para $\mathrm{Al}$

7. $\mathrm{NPK}+"$ dolomitico pas. $100 \%$ peneira 18 , para $\mathrm{A} 1$

8. $\mathrm{NPK}+"$ calcítico pas. $100 \%$ peneira 18 , para $\mathrm{Al}$

9. $\mathrm{NPK}+"$ dolomítico pas. $100 \%$ peneira 35 , para $\mathrm{Al}$

10. NPK + " calcítico pas. $100 \%$ peneira 35 , para Al

11. $\mathrm{NPK}+"$ dolomítico pas. $100 \%$ peneira 40 , para $\mathrm{Al}$

12. $\mathrm{NPK}+"$ calcítico pas. $100 \%$ peneira 40 , para $\mathrm{Al}$

13. $\mathrm{NPK}+"$ dolomitico pas. $100 \%$ peneira 50 , para $\mathrm{Al}$

14. $\mathrm{NPK}+"$ calcítico pas. $100 \%$ peneira 50 , para $\mathrm{Al}$

15. NPK + Calc. dol. legal $(100 \%$ pen. 10 e $50 \%$ pen. 50 para pH

16. NPK + Calc. cal. legal ( $100 \%$ pen. 10 e $50 \%$ pen. 50 para $\mathrm{pH}$

17. $\mathrm{NPK}+"$ dolomitico pas. $100 \%$ peneira 10 , para $\mathrm{pH}$

18. $\mathrm{NPK}+"$ calcítico pas. $100 \%$ peneira 10 , para $\mathrm{pH}$

19. NPK $+"$ dolomítico pas. $100 \%$ paneira 18 , para $\mathrm{pH}$

20. $\mathrm{NPK}+"$ calcitico pas. $100 \%$ pencira 18 , para $\mathrm{pH}$

21. $\mathrm{NPK}+"$ dolomitico pas. $100 \%$ peneira 35 , para $\mathrm{pH}$

22. $\mathrm{NPK}+"$ calcitico pas. $100 \%$ peneira 35 , para $\mathrm{pH}$

23. NPK + " dolomitico pas. $100 \%$ peneira 40 , para $\mathrm{pH}$

24. NPK + " calcítico pas. $100 \%$ peneira 40 , para $\mathrm{pH}$

25. $\mathrm{NPK}+"$ dolomitico pas. $100 \%$ peneira 50 , para $\mathrm{pH}$

26. $\mathrm{NPK}+"$ calcítico pas. $100 \%$ peneira 50 , para $\mathrm{pH}$

C.V. $\%$

\begin{tabular}{|c|c}
$\mid$\begin{tabular}{|c} 
Produçōes \\
de massa \\
seca
\end{tabular} \\
\hline milho & trigo \\
\hline$g$ & $g$ \\
36,0 & 37,3 \\
57,7 & 50,7 \\
96,3 & $\mathbf{7 3 , 5}$ \\
95,0 & $\mathbf{7 4 , 3}$ \\
99,3 & $\mathbf{7 5 , 3}$ \\
93,3 & $\mathbf{7 5 , 8}$ \\
96,3 & $\mathbf{7 7 , 2}$ \\
$\mathbf{8 8 , 0}$ & $\mathbf{7 6 , 5}$ \\
97,7 & $\mathbf{7 7 , 2}$ \\
96,0 & 69,3 \\
94,7 & $\mathbf{7 5 8}$ \\
95,0 & $\mathbf{7 8 , 3}$ \\
99,3 & $\mathbf{7 4 , 2}$ \\
98,0 & $\mathbf{7 3 , 5}$ \\
92,3 & $\mathbf{7 3 , 8}$ \\
94,7 & $\mathbf{7 3 , 7}$ \\
92,0 & $\mathbf{7 8 , 3}$ \\
91,7 & $\mathbf{7 7 , 3}$ \\
92,0 & $\mathbf{7 5 , 5}$ \\
91,3 & $\mathbf{7 5 , 5}$ \\
89,7 & $\mathbf{7 5 , 8}$ \\
90,0 & $\mathbf{7 7 , 7}$ \\
$\mathbf{9 1}, 7$ & $\mathbf{7 7 , 3}$ \\
$\mathbf{8 5 , 7}$ & $\mathbf{7 3 , 7}$ \\
89,7 & $\mathbf{7 6 2}$ \\
91,3 & $\mathbf{7 6 , 0}$ \\
\hline & \\
$\mathbf{8 , 0}$ & 4,5 \\
28,9 & 12,7 \\
& \\
\hline
\end{tabular}

o materia: que passou em $100 \%$ através de peneira de malha 50 . Todas as granulometrias estudadas apresentaram a mesma resposta, todas significativas para os tratamentos sem calcário, porém entre elas não se observaram diferenças. Esses dados não concordam com os obtidos por Anderson (1), que mostrou em seu trabalho que o calcário dolomítico de granulometria mais grossa que 40-mesh não apresentou efeito na elevação do $\mathrm{pH}$, mesmo após quatro semanas da aplicação. Comparando-se dentro de cada granulometria os efeitos dos calcários calcíticos e dolomíticos, observou-se que os dois materiais possuem 
igual ação no aumento de produção de massa seca de milho. Não se observou diferença alguma entre os dois materiais em todas as granulometrias estudadas, porém pesquisas de Beacker e outros (2) apontaram que o calcário calcítico é mais eficiente que o dolomitico. Trabalhos de Verlêngia e Gargantini (8) mostraram que o calcário dolomítico apresentou melhores resultados que o calcítico, na elevação do $\mathrm{pH}$.

Considerando que os materiais estudados foram obtidos pela passagem em $100 \%$ nas peneiras com 10, 20, 30, 40 e 50-mesh, isso lugicamente abrange materiais com granulometria muito fina. Como explicam Meyer e Volk (6), particulas com granulometrias mais grossas que 50-mesh necessitam de 18 meses para apresentar seus efeitos totais, porénı neste trabalho já são observados excelentes respostas para corretivos que passam através de peneira de $2 \mathrm{~mm}$ de malha. Não foi observada diferença estatística entre todos os tratamentos que receberam os dois calcários e para todas as granulometrias.

Somente para o tratamento 24 é que nāo foi constatada diferença estatistica em relação ao tratamento NPK sem calcário, mas não foi encontrada explicaçāo razoável para o fato.

Os resultados analiticos das amostras de solo, constantes do quadro 2, mostram que as quantidades de calcários aplicadas apresentaram algum efeito, porém não o esperado. Assim, nos tratamentos onde foram aplicados calcários dolomiticos ou calcíticos nas quantidades para eliminar o aluminio, verificou-se que onde foram usados materiais que passavam em $100 \%$ em peneira 10 e 20 aquele elemento não foi totalmente insolubilizado. $\mathrm{O} \mathrm{pH}$ foi muito pouco alterado nesses tratamentos, porém as quantidades de cálcio mais magnésio foram aumentadas. O emprego de materiais mais finos que 20-mesh foi eficiente para eliminar o aluminio.

Quando se utilizaram materiais corretivos nas. quantidades necessárias para elevar o $\mathrm{pH}$ ao redor de 6,50, as anostras analisadas não apresentaram mais alumínio trocável, e as quantidades de cálcio mais magnésio foram grandemente aumentadas. A influência da granulometria dos calcários nos aumentos dos valores de $\mathrm{pH}$ foi bastante sensível, assim como nos teores do cálcio mais magnésio, que sofreram aumento com a granulometria do material utilizado. Assim, onde os calcários entraram com a granulometria mais grosseira, como $100 \%$ passando através de peneira de 30-mesh, os valores de pH não ascenderam a mais de 5,90 , enquanto que nos tratamentos que receberam 
QUADRO 2. - Resultados analíticos médios, de três repetiçōes, dos solos dos vasos do ensaio de competição entre dois calcários, em diversas granulometrias e quantidades, em culturas de milho e trigo (*)

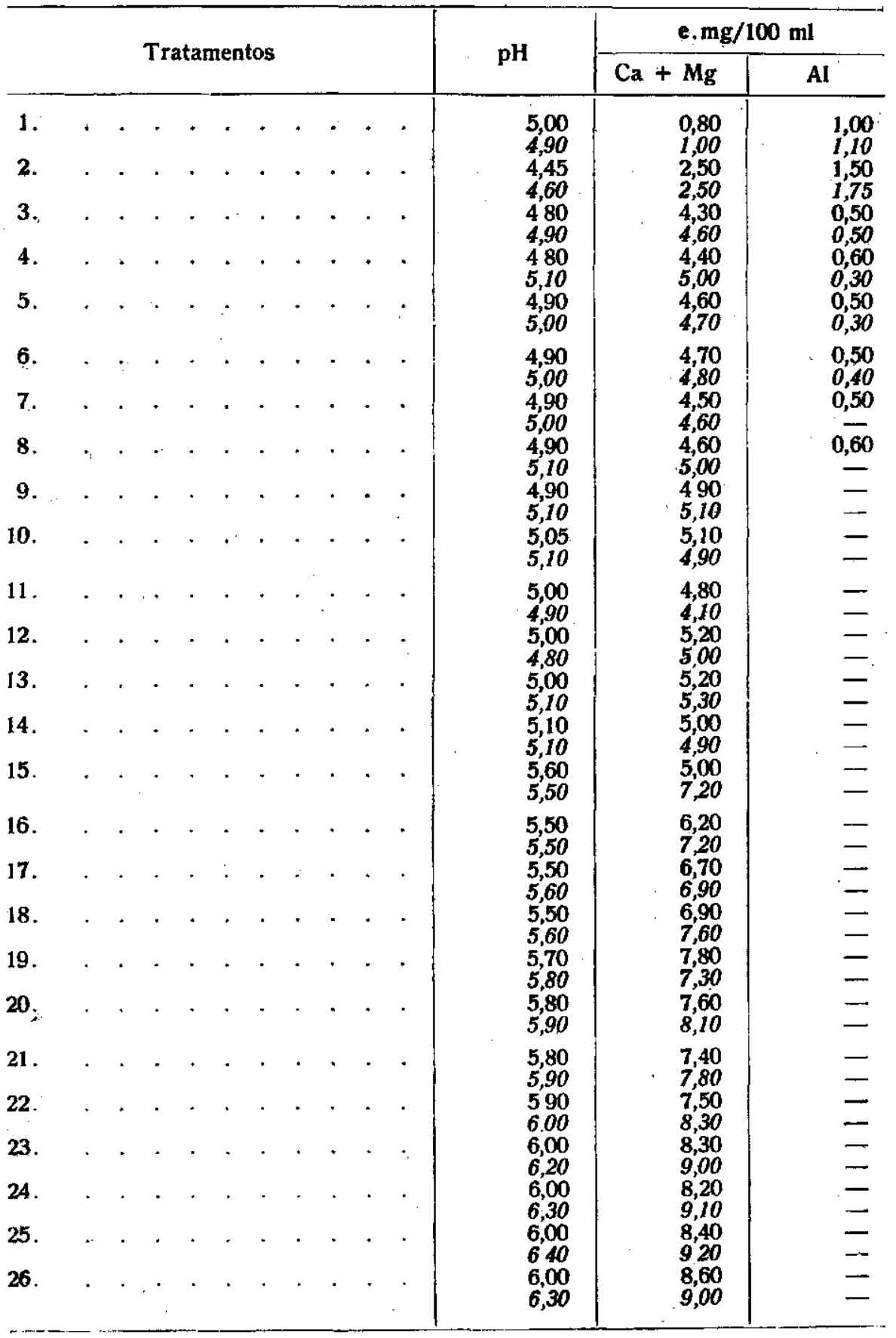

(*) Algarismos arábicos, correspondem as análises efetuadas no solo apos a colheita do milho; em itálico, as análises efetuadas no solo apos a colheita do trigo. 
material passando através de peneiras mais finas, esses valores apresentaram-se sempre acima de 6,00. Os dados aqui obtidos confirmam os de Verlêngia (8), que também verificou que em curto espaço de tempo materiais corretivos da acidez com granulometria mais grossa que 30-mesh não eliminaram os teores de aluminio trocável e pouco influenciaram os valores de $\mathrm{pH}$. Anderson (1) também afirma que corretivos com granulometria acima de 40-mesh não apresentaram efeito nas modificações dos valores de $\mathrm{pH}$ do solo.

\section{2 - ENSAIO COM TRIGO}

Os dados de produção de massa seca, obtidos na cultura de trigo (quadro 1), mostram claramente que o efeito dos corretivos da acidez foi bastante sensível. Pela análise dos resultados obteve-se confirmação dos efeitos comentados para a produção de massa seca para o milho. Foi observada diferença estatística entre o tratamento testemunha e o que recebeu adubação NPK, sem corretivo. Todos os tratamentos que receberam aplicação de calcário apresentaram-se estatisticamente superiores aos que não receberam esse tratamento. Não foi obsrvada diferença entre os dois calcários estudados, o que mostra que o dolomítico e o calcítico são igualmente eficientes para o aumento de produção de massa seca das culturas estudadas. Entre todas as granulometrias também não foi observada diferença, o que indica que tanto para o material dentro da granulometria exigida por Lei, como para o passando em peneira de malha bastante fina, como a de 50-mesh $(0,297 \mathrm{~mm})$, os resultados foram iguais estatisticamente.

Os solos dos vasos foram novamente submetidos a análises, e os resultados mostraram que para as granulometrias até 30-mesh ainda foram observados valores de aluminio; isso mostra que até essa granulometria, apesar de novas aplicações de calcários recebidas, ainda não houve a insolubilidade completa desse elemento. Os teores de cálcio mais magnésio foram maiores que os anteriormente analisados e os valores de $\mathrm{pH}$ foram crescentes com a granulometria do material utilizado. Quando a granulometria era mais fina, maiores eram os valores de $\mathrm{pH}$ observados, mostrando isso o efeito benéfico da granulometria do calcário na elevação do $\mathrm{pH}$ do solo. As mesmas considerações já tecidas para as análises após a cultura de milho são válidas para estas novas amostras, onde se patenteia a importância da granulometria no aumento dos valores de $\mathrm{pH}$ em função do tempo necessário para a sua ação. 
Os valores de $\mathrm{pH}$ foram pouco alterados nos tratamentos que receberam calcário em quantidades suficientes para eliminar o alumínio, ao passo que sofreram grandes alteraçōes quando as quantidades dos corretivos foram aplicadas para elevar o $\mathrm{pH}$ a 6,50, porém, também neste caso, os valores de $\mathrm{pH}$ foram mais altos quanto mais fino o material aplicado.

\section{4 - CONCLUSÖES}

As seguintes conclusões podem ser tiradas:

a) Os calcários calcíticos e dolomíticos apresentaram os mesmos efeitos no aumento de produção de nıassa seca de milho e de trigo.

b) Não foi observada diferença em efeito para as diferentes granulometrias dos corretivos.

c) As quantidades de calcários, utilizadas simplesmente para eliminar o aluminio, foram suficientes para a obtenção das maiores produções, iguais às obtidas quando o solo recebeu calagem para elevar o $\mathrm{pH}$ a próximo de 6,50 .

\section{EFFECT OF PARTICLE SIZE OF CALCITIC AND DOLOMITIC LIMESTONE ON SOIL NEUTRALIZATION}

\section{S U M M A R Y}

Greenhouse experiments were carried out with wheat and corn with the purpose to study the effects of particle size of calcitic z 7 d dolomitic limestones in the neutralization of soil acidity and on crops growth.

The results showed that calcitic and dolomitic limestones had the same effect on soil acidity. Particle size had little effect on yields but finer particles were more effective in the neutralization of soil acidity.

\section{LITHRATURA CITADA}

1. ANDERSON, C. A. Effect of particle size of calcitic and dolomitic limestone on rate of reaction in Lakland fine sand. Proc. Soil Crop Sci. Fla $28: 63-69,1968$.

2. BEACKER, B. L.; LONGENECKER, D. \& MERKLE, F. G. Influence of form, fineness, and amount of limestone on plants development and certain soil characteristics. Soil Sci. 73:75-82, 1952. 
3. GALlo, J. R.; CATANI, R. A. \& GARGANTINI, H. Efeito de très tipos de calcários na reação do solo e no desenvolvimento da soja. Bragantia 15:121-130, 1956 .

4. GARGANTINI, H.; COELHO, F. A. S.; VERLENGIA, F. \& SOARES, E. Levantamento de fertilidade dos solos do Estado de São Paulo. Campinas, Instituto Agronômico, 1970. 32p.

5. —; CONAGIN, A. \& PURCHIO, M. J. Ensaio de adubação NPK em cultura de trigo. Bragantia 17:12-27, 1958.

6. MEYER, T. A. \& VOLK, G. W. Effect of particle size of limestone on soil reaction, exchangeable cations, and plant growth. Soil Sci. 73:37-52, 1952.

7. SHAW, W. M. \& ROBINSON, B. Reaction efficiencies of liming materials as indicated by lisimeter leachate composition. Soil Sci. 89:209-218, 1960.

8. VERLENGIA, F. \& GARGANTINI, H. Estudo sobre a eficiência de diferentes fraçōes granulométricas de calcários no solo. Bragantia 31: $119-128,1972$. 